\title{
Recurrent Prostate Carcinoma
}

National Cancer Institute

\section{Source}

National Cancer Institute. Recurrent Prostate Carcinoma. NCI Thesaurus. Code C7902.

Prostate carcinoma reemerging after a period of remission. 